\title{
Radiation protection in Dentomaxillofacial Radiology Installation
}

\author{
Mohammad Adib Redzuan Lee*, Fahmi Oscandar*, Ria Noerianingsih Firman* \\ *Department of Dentomaxillofacial Radiology Faculty of Dentistry Universitas Padjadjaran
}

\begin{abstract}
Introduction: ICRP produces recommendations for radiation protection concerning among them, patient, personnel and surrounding. The supervision for radiation protection in Dentomaxillofacial Radiology Installation RSGM-UNPAD and PP-UM must be as according to the national regulations. The purpose of study is how is the radiation protection and PP-UM, and what factors that influence radiation protection. Methods: Descriptive of qualitative research method with questionnaire technique with observational and interview survey, done to describe radiation protection with ALARA principle, taken in both Dentomaxillofacial Radiology Installation of RSGM-UNPAD and PP-UM. Result: Although few criteria like, lead apron lead protective glove, gonad lead barrier for personnel or operator, and, pass box and film storage for surrounding, radiation protection were not met by both installations, thyroid collar for patient radiation protection was met in PP-UM while not in RSGM-UNPAD. Conclusion: Radiation protection in Dentomaxillofacial Radiology Installation of RSGM-UNPAD have the advantage of systematic and central way of enforcement of regulation, and the weakness of its standard of radiation protection was not comprehensive, while PP-UM have the advantage of high supervision and adequate of instruments for patient radiation protection, and the weakness of its standard of radiation protection was not comprehensive. Factors influence the result were due to unavailable of SOP, insufficient of funds, inadequate of instruments, low supervision, and difficulty in bureaucracy approval.
\end{abstract}

Key words: Radiation Protection, Radiology Installation, UNPAD, UM

\section{INTRODUCTION}

Since the $19^{\text {th }}$ century, many discoveries related to radiography have already been made. Only later in 1895 Wilhelm Conrad Röntgen, a German physicist produced the first ever radiographic photo. Not long after Wilhem Röntgen's radiographic discovery, there has been discovery of radiation and its associated hazards. ${ }^{1}$

Olineus reports that in 1936 erected in
Hamburg by the German Röntgen Society, several hundred medical workers of many nationalities died from radiation damage. ${ }^{2}$ There was no doubt that radiation protection was significant to avoid radiation damage. ICRP features the recommendations for radiation protection since 1928 up to the most recent in 2010 through its worldwide publications. ${ }^{3}$

Indonesia, runs by presidential system as a unitary state with its power concentrated in the 
central government. Under the Act No.31 Year 1964 on Nuclear Energy, the control of nuclear energy uses a bureau inside National Atomic Energy Agency (BATAN) while under the Act No.10 Year 1997 on Nuclear Energy, BATAN is in position as Promotional Body and National Nuclear Energy Regulatory Agency (BAPETEN) as Regulatory Body. In the Presidential Decree No. 76 Year 1998, BAPETEN is under and directly responsible to the President of Republic of Indonesia, and BAPETEN receives the budget from the Government. ${ }^{4}$

Universitas Padjadjaran (UNPAD) Faculty of Dentistry was established on $1^{\text {st }}$ of September 1959 is an institution for dental professions, undergraduates, postgraduates and learning that has always been as referral from many other education institution, clinics and hospitals. Its Dentomaxillofacial Radiology Installation is fully equipped and organized to such manner that synchronized to the need of the Hospital Dental health care. ${ }^{5}$

Malaysia is a federal constitutional elective monarchy of Yang di-Pertuan Agong that runs with the parliamentary system as the Prime Minister being the head of the government. The Atomic Energy Licensing Act is supported by sets of regulations has a clause, which allows for the formation of Atomic Energy Licensing Board (AELB) as the highest authority to enforce the requirements of the Act and its subsidiary legislations concerning radiation protection. The Ministry of Health $(\mathrm{MOH})$, under which AELB is operating, has allocated enough funds to ensure that the legal functions and responsibilities of the Board are carried out as prescribed by the Act, hence most of the regulations were drafted based on earlier recommendations of International Atomic Energy Agency (IAEA). ${ }^{6}$

University Malaya (UM) Faculty of Dentistry was set up in 1971; was the first and most established dental school in Malaysia. It's General Practice and Oral and Maxillofacial Radiology department of Faculty of Dentistry is infamous with its high standard of teaching, research and professionalism that correlates to its hospital. ${ }^{7}$

Standard Operational or Operating Procedure (SOP) for radiation protection in installation was available in RSGM-UNPAD. ${ }^{8}$ As stated in the law, Menteri Kesehatan, Republik Indonesia Nomor 340/MENKES/PER/III/ 2010, all Class of Hospital in Indonesia are required to have SOP in order to function as hospital and health service. Standard Radiation Protection from regulation body in RSGM-UNPAD was explicit as stated in Indonesia law, UU Kesehatan No 36/2009, ${ }^{9}$ and Peraturan Badan Pengawas Tenaga Nuklir Nomor 8 Tahun 2011, ${ }^{10}$ for diagnostic x-ray radiation protection. The supervision for radiation protection in RSGM-UNPAD seems to be tight. ${ }^{11}$ Hence, author's hypothesis is radiation protection RSGM-UNPAD is comprehensive.

Standard Operational or Operating Procedure (SOP) for radiation protection in installation was unavailable in PP-UM. SOP was not stated in the Laws of Malaysia/Act 304/ Atomic Energy Licensing Act 1984. ${ }^{12}$ Standard Radiation Protection from regulation body in PP-UM was implicit as many criteria concerning radiation protection was only generally implied as in the law, Warta Kerajaan Malaysia, Seri Paduka Baginda, Atomic Energy Licensing ACT 1984/Basic Safety Radiation Protection/Regulations 2010. ${ }^{13}$ There is supervision for radiation protection in PP-UM but to what level is unknown. ${ }^{7}$ Hence the hypothesis by author is radiation protection PP. UM is not comprehensive.

Through author's observation, the supervision for radiation protection in Dentomaxillofacial Radiology Installation RSGMUNPAD is very tight as according to regulation set by the government. This creates author's interest to study on how the condition for radiation protection in RSGM-UNPAD; with similar interest of study in PP-UM.

The standard of radiation protection surveyed in this research concerns the scope of radiation protection for patient, personnel or operator, and surroundings; each scope concerning system or regulation, instrument or tools, and technique. The purpose of study is how is the radiation protection and PP-UM, and what factors that influence radiation protection.

\section{METHODS}

This study done through simple descriptive of qualitative research method with questionnaire technique as a data collecting method. ${ }^{14}$ The Dentomaxillofacial Radiology Installation in RSGMUNPAD and PP-UM are represented as samples. 
The material to obtain primary data were in questionnaire form of observation survey and interview survey taken in both Dentomaxillofacial Radiology Installation RSGM-UNPAD and PP-UM were as according to the ICRP recommendations from each national regulations respectively. ${ }^{10}$, ${ }^{12}$ Observation survey was done by author in a passive manner where the author observes and is not involved in the activity of the people in the vicinity. Interview survey was done by author with a questionnaire structure to Radiology personnel, operators, Radiologist, and Radiographers in random as anonymous with prepared complete structured of questions. Data were collected, discussed, summarized and factors that influenced the result were justified

\section{RESULTS}

Table 1. Checklist A (Observational Survey)

\begin{tabular}{|c|c|c|c|c|c|}
\hline & \multirow{3}{*}{ Text } & \multicolumn{4}{|c|}{ A (Observational Survey) } \\
\hline & & \multicolumn{2}{|c|}{ UNPAD } & \multicolumn{2}{|c|}{ UM } \\
\hline & & Yes & No & Yes & No \\
\hline \multicolumn{6}{|c|}{ A. Patient Radiation Protection: } \\
\hline \multicolumn{6}{|c|}{ 1. Instruments/Tools for Patient: } \\
\hline i. & Provide complete radiation protection for Patient & s & & r & \\
\hline ii. & Using Aluminium Filters & r & & r & \\
\hline iii. & Using Lock Adjustment & s & & r & \\
\hline iv. & Using Lead Collimator & r & & s & \\
\hline v. & Using Position-Indicating Device & r & & s & \\
\hline vi. & Using Thyroid Collar & & r & 2 & \\
\hline vii. & Using Lead Apron & r & & r & \\
\hline viii. & Using Fast Film & s & & s & \\
\hline ix. & Using Film-Holding Device & r & & t & \\
\hline \multicolumn{6}{|c|}{ 2. Technique for Patient: } \\
\hline i. & Using Exposure Factor Selection & r & & s & \\
\hline ii. & Using Conventional Dental X-ray & s & & c & \\
\hline iii. & Using Digital Dental X-ray & r & & s & \\
\hline iv. & Using Film Processing System & r & & s & \\
\hline \multicolumn{6}{|c|}{ B. Personnel/Operator Radiation Protection: } \\
\hline \multicolumn{6}{|c|}{ 1. System/Regulation for Personnel/Operator: } \\
\hline i. & Preserve Patient's Data in a System. & r & & ऽ & \\
\hline \multicolumn{6}{|c|}{ 2. Instruments/Tools for Personnel/Operator: } \\
\hline i. & $\begin{array}{l}\text { Using Lead Apron (minimum } 0,25 \mathrm{~mm} \mathrm{~Pb} \text { ) which covers the body and gonad organs } \\
\text { from direct or indirect radiation exposure. }\end{array}$ & & ऽ & & s \\
\hline ii. & $\begin{array}{l}\text { Using Lead Protective Glove (minimum 0,25 mm Pb) which covers hands and wrist } \\
\text { from direct or indirect radiation exposure. }\end{array}$ & & s & & s \\
\hline iii. & Using Gonad Lead Barrier (minimum 0,5 mm Pb). & & s & & s \\
\hline iv. & Using Film Badge or any other Radiation Monitoring Device. & r & & s & \\
\hline \multicolumn{6}{|c|}{ 3. Technique for Personnel/Operator: } \\
\hline i. & Using Conventional Dental X-ray. & r & & s & \\
\hline ii. & Using Digital Dental X-ray. & r & & s & \\
\hline \multicolumn{6}{|c|}{ C. Surrounding Radiation Protection: } \\
\hline \multicolumn{6}{|c|}{ 1. System/Regulation for Surrounding: } \\
\hline i. & Provide Radiation Protectionfor surrounding community near Radiation Premises. & r & & s & \\
\hline ii. & Intraoral Dental X-ray Device is equipped with Cone. & t & & t & \\
\hline
\end{tabular}




\begin{tabular}{|c|c|c|c|c|c|}
\hline & \multirow{3}{*}{ Text } & \multicolumn{4}{|c|}{ A (Observational Survey) } \\
\hline & & \multicolumn{2}{|c|}{ UNPAD } & \multicolumn{2}{|r|}{ UM } \\
\hline & & Yes & No & Yes & No \\
\hline \multicolumn{6}{|c|}{ iii. Cone has these description: } \\
\hline a & Length of Cone is not less than $20 \mathrm{~cm}$ for operating tube above $60 \mathrm{kV}$. & r & & r & \\
\hline b & Length of Cone is not less than $10 \mathrm{~cm}$ for tube of $60 \mathrm{kV}$. & r & & r & \\
\hline c & Diameter of Cone is not more than $6 \mathrm{~cm}$. & s & & r & \\
\hline iv. & If there is window in the Radiating area, it is 2 meter above the floor. & r & & r & \\
\hline v. & Following the guidelines: & s & & r & \\
\hline a & $\begin{array}{l}\text { Minimum area for Diagnostic X-ray Device is } 4 \text { meter length, } 3 \text { meter width and 2,8 } \\
\text { meter height, excluding operator's cabin, patient's cabin; in case of window position, it } \\
\text { is } 2 \text { meter height. }\end{array}$ & & 厂 & ऽ & \\
\hline a. & $\begin{array}{l}\text { Minimum area for Dental X-ray Device is 3meter length, } 2 \text { meter width and 2,8 meter } \\
\text { height. }\end{array}$ & r & & r & \\
\hline b. & $\begin{array}{l}\text { The width of wall is } 20 \mathrm{~cm} \text { Beton or } 25 \mathrm{~cm} \text { Red Bricks with density of } 2,2 \mathrm{gr} / \mathrm{cm} 3 \text { or } \\
\text { equivalent to } 2 \mathrm{~mm} \mathrm{~Pb} \text {. }\end{array}$ & J & & 厂 & \\
\hline a & Dark Room description: & s & & r & \\
\hline 1. & Area of 3 meter length, 2 meter width and 2,8 meter height. & & & & \\
\hline 2. & Equiped with clean water at all time. & s & & J & \\
\hline 3. & Good Air Circulation. & s & & r & \\
\hline vi. & Installed of Radiation Notice sticker on Radiating Area. & & & & \\
\hline vii. & Installed of Caution Radiation Warning. & & & & \\
\hline viii. & Installed and Operating of Red Light indicator for Radiating Exposure. & r & & s & \\
\hline \multirow[t]{2}{*}{ ix. } & Follow the guidance: & & & & \\
\hline & $\begin{array}{l}6 \text { feet away between } 90 \text { o to } 1350 \text { from patient's exposure or other safety barrier } \\
\text { distance. }\end{array}$ & & 厂 & & r \\
\hline \multicolumn{2}{|r|}{ 2. Instruments/Tools for Surrounding } & & 厂 & & r \\
\hline i. & Diagnostic X-ray beam instruments has at least: & & & & \\
\hline a & Supporting tube rod. & s & & r & \\
\hline b. & Collimator. & & & & \\
\hline c. & Tension Instrumentation. & & & & \\
\hline ii & Using Radiation Barrier (minimum 1,5 mm Pb). & & & & \\
\hline iii. & Using Radiation Barrier for Safety Window (minimum 1,5 mm Pb). & & & & \\
\hline iv. & Using Pass Box (minmum 0,5 mm Pb). & & & & \\
\hline v. & Using Film Storage for unprocessed film (minimum 2,0 mm Pb). & & & & \\
\hline vi. & There is Continuant of Barrier between Barriers. & & & & \\
\hline \multicolumn{6}{|c|}{ 3. Technique for Surrounding: } \\
\hline \multirow[t]{2}{*}{ i. } & Operation of Diagnostic X-ray Device: & & & & \\
\hline & $\begin{array}{l}\text { X-ray Device is operated with the Primary Radiation directed to 'minimal placement } \\
\text { factor area'. }\end{array}$ & & & & \\
\hline ii. & $\begin{array}{l}\text { The direction of X-ray exposure is not directed to panel control, weaker radiation } \\
\text { barrier, or simply Using X-ray. }\end{array}$ & & & & \\
\hline
\end{tabular}

The description of radiation protection in RSGM-UNPAD and PP-UM is presented. Based on the Table 1, the description of radiation protection from an observational survey done, both UNPAD and UM provide complete radiation protection, use aluminium filters, lead collimator, lock adjustment, position-indicating device, lead apron, fast film, film-holding device, provide the use of exposure factor selection, conventional dental $x$-ray, digital dental $x$-ray and film processing systems or tools for patient radiation protection.

Both installations preserve patient's data in a system, use film badge for radiation monitoring device, conventional and digital dental $\mathrm{x}$-ray 
imaging for personnel or operator radiation protection. Also, both installations provide radiation protection for surrounding community near radiation premises, use of intraoral dental $x$-ray device that is equipped with cone with standard description, follow the standard of placement of window in the radiating area, follow the guidelines for minimum area for diagnostic $x$-ray device, dental x-ray device, width of wall of beton, red bricks or lead width equivalent, dark room description, installed radiation notice sticker, caution radiation warning, red light indicator for radiating exposure, follow the guideline of radiating safety distance use diagnostic $x$-ray beam that has at least the supporting tube rod, lead collimator, tension instrumentation, use of radiation barrier, radiation barrier for safety window and continuant barrier between barriers, operate the diagnostic $\mathrm{x}$-ray device with the primary radiation directed to 'minimal placement factor area', and direction of $\mathrm{x}$-ray exposure not to direct to panel control, weaker radiation barrier or simply the use of $x$-ray devices for surrounding radiation protection. UNPAD does not use thyroid collar for patient radiation protection, whereas UM uses for intraoral radiograph technique. Both installations do not use lead apron, lead protective glove and gonad lead barrier, for its personnel or operator

Table 2 Checklist B (Interview survey)

\begin{tabular}{|c|c|c|c|c|c|}
\hline & \multirow{3}{*}{ Text } & \multicolumn{4}{|c|}{ B (Interview Survey) } \\
\hline & & \multicolumn{2}{|c|}{ UNPAD } & \multicolumn{2}{|l|}{ UM } \\
\hline & & Yes & No & Yes & No \\
\hline \multicolumn{6}{|c|}{ A. Patient Radiation Protection: } \\
\hline \multicolumn{6}{|c|}{ 1. System/Regulation for Patient: } \\
\hline i. & $\begin{array}{l}\text { Evaluate patient's condition to monitor radiation exposure before and } \\
\text { after exposure. }\end{array}$ & r & & s & \\
\hline ii. & $\begin{array}{l}\text { Evaluate patient's condition to limit radiation exposure with ALARA } \\
\text { before and after exposure. }\end{array}$ & r & & r & \\
\hline iii. & Evaluate any Radiation Accidents from Clinical Aspect. & r & & s & \\
\hline iv. & Has Patient's Safety Standard or Guidelines. & r & & s & \\
\hline v. & $\begin{array}{l}\text { Has a Standard of Procedure Criteria for Pregnant Ladies in radiation } \\
\text { exposure. }\end{array}$ & r & & s & \\
\hline vi. & $\begin{array}{l}\text { Has a Standard of Procedure Criteria for Paediatric patients in radiation } \\
\text { exposure. }\end{array}$ & r & & r & \\
\hline vii. & Consult Radiologist for Clinical Indication and Temporary Diagnosis. & r & & s & \\
\hline viii. & Consult Radiologist for Final Diagnosis & r & & s & \\
\hline ix. & $\begin{array}{l}\text { Transferring of radiographic data from one Hospital tol another avoid } \\
\text { retaking radiography. }\end{array}$ & r & & $\checkmark$ & \\
\hline $\mathrm{x}$. & Quality Control of X-ray device is certified. & r & & s & \\
\hline xi. & Quality Control of X-ray device is evaluated routinely. & r & & s & \\
\hline xii. & Repair and Maintenance of X-ray device is done routinely. & s & & s & \\
\hline xiii. & $\begin{array}{l}\text { Only the patient taking radiographic photo alone can be in the } \\
\text { radiating area, unless required Patient's Assistant. }\end{array}$ & r & & ऽ & \\
\hline \multicolumn{6}{|c|}{ 2. Instruments/Tools for Patient: } \\
\hline i. & Provide complete radiation protection for Patient. & r & & 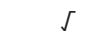 & \\
\hline ii. & Using Fast Film. & r & & $\checkmark$ & \\
\hline iii. & Using Film-Holding Device. & r & & J & \\
\hline \multicolumn{6}{|c|}{ 3. Technique for Patient: } \\
\hline i. & $\begin{array}{l}\text { Implementing the right Techniques and Procedures to reduce/limit the } \\
\text { radiation exposure towards Patient. }\end{array}$ & r & & s & \\
\hline ii. & $\begin{array}{l}\text { Implementing the optimal radiation protection and safety with ALARA for } \\
\text { diagnostic purpose. }\end{array}$ & s & & $\checkmark$ & \\
\hline
\end{tabular}




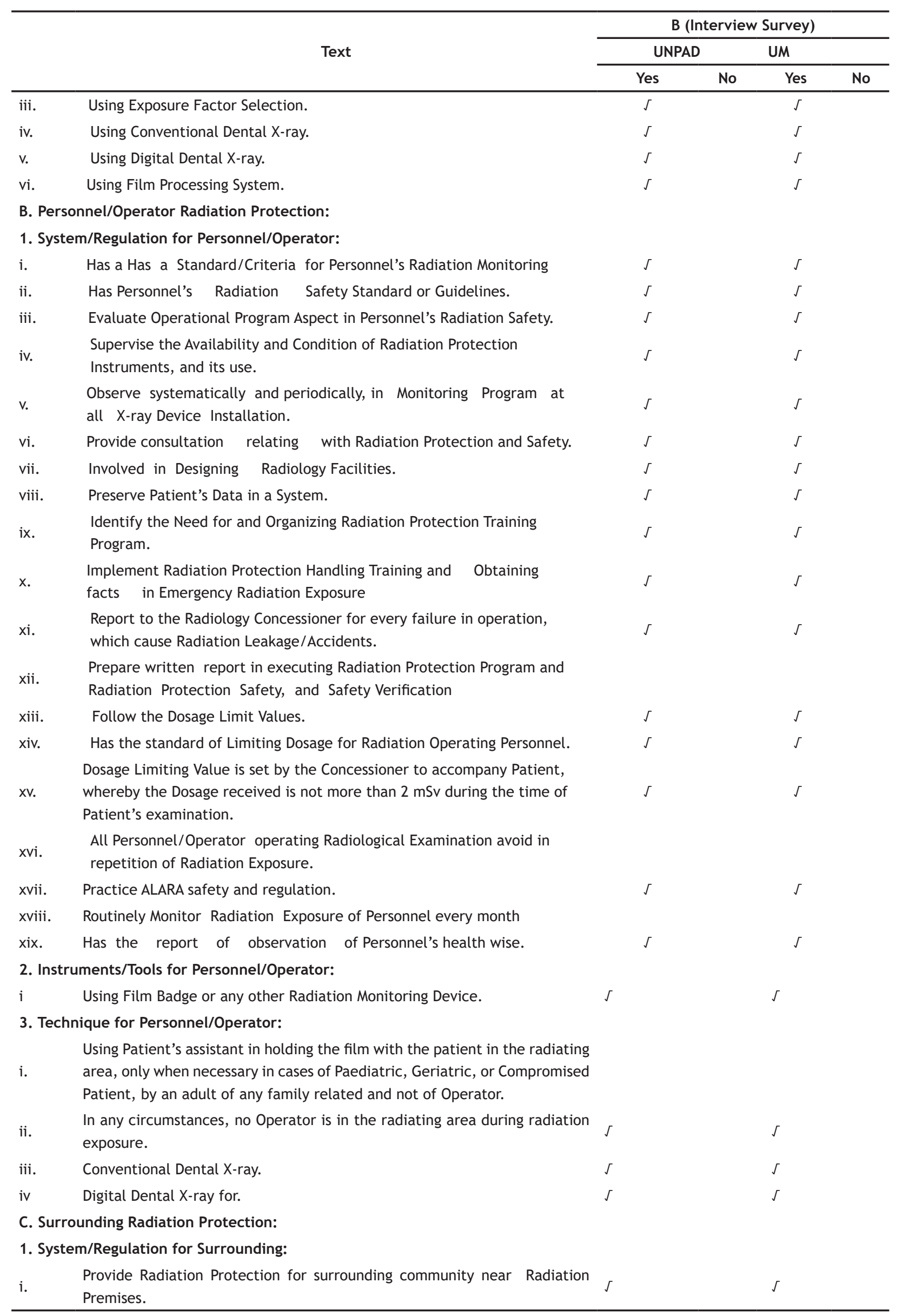




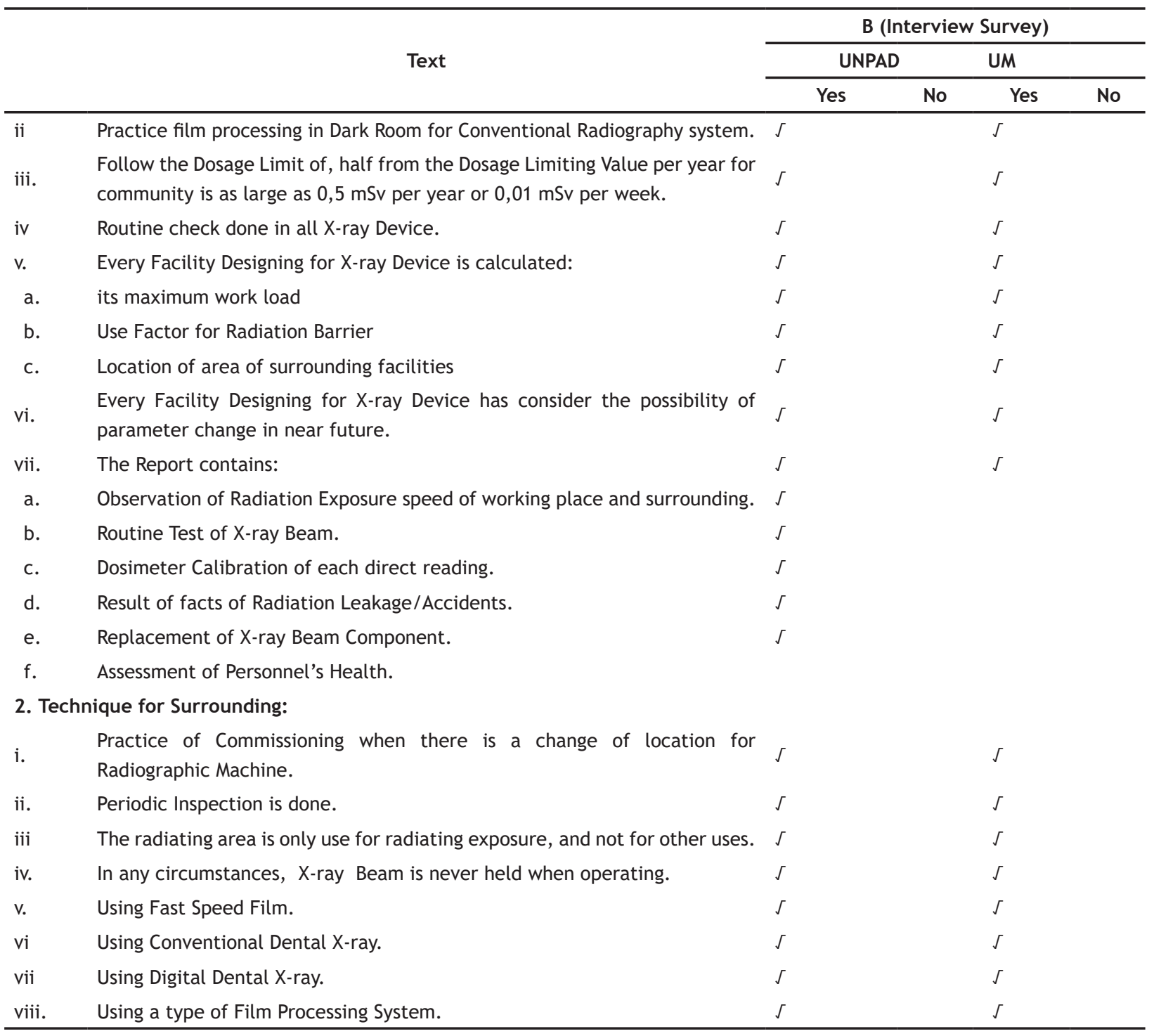

radiation protection. Both installations did not use pass box, and film storage for unprocessed film for surrounding radiation protection.

Based on Table 2, the description of radiation protection from an interview survey done, both UNPAD and UM do evaluate patient's condition to monitor radiation exposure, evaluate patient's condition to limit radiation exposure with ALARA, evaluate any radiation accidents, have patient's safety standard, have a standard procedure criteria for pregnant ladies, have a standard of procedure criteria for pediatrics, consult radiologist for clinical indication and temporary diagnosis, consult radiologist for final diagnosis, agreed that transferring radiographic data avoid retaking radiograph, quality control of $x$-ray device is certified, quality control of $x$-ray device is evaluated routinely, repair and maintenance of $x$-ray device is done routinely, and practice only the patient taking radiographic photo alone can be in the radiating area, unless required patient's assistant, provide complete radiation protection for patient, use of fast film, use of film-holding device, implementing the right technique and procedure to limit radiation exposure, implementing the optimal radiation safety with ALARA, use exposure factor selection, conventional dental $x$-ray, digital dental $x$-ray and film processing system for patient radiation protection.

Both installations have a personnel's radiation safety standard, evaluate operational program aspect in personnel's radiation safety, supervise availability and condition of radiation protection instruments, observe monitoring program at all $\mathrm{x}$-ray device, provide consultation 
relating to radiation safety, involved in designing radiology facilities, preserve patient's data in a system, identify and organize radiation protection training program, implement radiation protection handling training with obtaining facts in emergency radiation exposure, claimed to report any radiation leakage, prepare written report in radiation protection, follow dosage limit values, have standard limiting dosage, dosage limiting value set by concessioner, avoids repetition of radiation exposure, practice ALARA safety, routinely monitor radiation exposure monthly, have health report, use film badge for monitoring device, use patient's assistant if necessary of any adult related family; not of operator, claimed no operator allowed in radiating area during radiation exposure, and use conventional dental $\mathrm{x}$-ray and digital dental $\mathrm{x}$-ray for personnel or operator radiation protection.

Correspondingly, both UNPAD and UM provide radiation protection near radiation premises, practice film processing in dark room for conventional system, follow dosage limit, routinely check all $x$-ray device, calculated each designed facility for its maximum work load, use factor for radiation barrier, location area of surrounding facilities, claimed to consider possibility of parameter change in near future for all x-ray device, and has report that contains observation radiation exposure speed of working place and surrounding, routine test $\mathrm{x}$-ray beam, dosimeter calibration of each direct reading, facts of radiation leakage or accidents, replacement of $x$-ray beam component, assessment of personnel's health, practice of commissioning when there is change of location for any radiation device, claimed that periodic inspection is done, radiating area is only for radiating exposure, $\mathrm{x}$-ray beam is never held when operating, use fast speed film, conventional dental $x$-ray, digital dental $x$-ray, and use type of film processing system for surrounding radiation protection.

As a result all interview survey criteria were met in both installations; through observational survey, although few criteria like lead apron, lead protective glove and gonad lead barrier for personnel or operator, and, pass box and film storage for surrounding, radiation protection were not met by both installations, thyroid collar for patient radiation protection was used in PP-UM while not in RSGM-UNPAD.

\section{DISCUSSION}

Criteria such as complete radiation protection, using aluminum filters, lead collimator, position-indicating device, lead apron, fast film, film-holding device, using exposure factor selection, conventional dental x-ray, and digital dental $\mathrm{x}$-ray and film processing system for patient radiation protection were followed by both installations. These criteria were met by UNPAD because of availability of SOP, adequate instruments, and high supervision; whereas in UM although the SOP was unavailable, it has the advantage of adequate instruments and high supervision.

Consequently, UNPAD does not use thyroid collar for patient radiation protection, whereas UM uses thyroid collar for intraoral radiograph technique. Although there were unavailable of SOP, due to high supervision and adequate instrument, the criteria was met in UM; whereas in UNPAD, although SOP was available, due to low supervision, inadequate of instrument, insufficient of funds and difficulty in obtaining bureaucracy approval made the criteria not met.

Accordingly, both UNPAD and UM do not use lead apron for its personnel or operator radiation protection. Although in UNPAD SOP was available, there were inadequate of instrument and may be due to insufficient of funds; whereas in UM SOP was unavailable, there were inadequate of instrument and may be due to insufficient of funds.

Correspondingly, both UNPAD and UM do not use lead protective glove, and gonad lead barrier for its personnel or operator radiation protection. Although in UNPAD SOP was available, there were low supervision on the criteria, inadequate of instrument and may be due to insufficient of funds; whereas in UM SOP was unavailable, there were low supervision on the criteria, inadequate of instrument and may be due to insufficient of funds.

Criteria of using conventional dental x-ray and digital dental $\mathrm{x}$-ray as technique for personnel or operator radiation protection were met by both UNPAD and UM. These criteria were met by UNPAD because of availability of SOP, adequate instruments, and high supervision; whereas in 
UM although the SOP was unavailable, it has the advantage of adequate instruments and high supervision.

Other criteria such as in providing radiation protection for surrounding community near radiation premises, intraoral dental $x$-ray device equipped with cone with standard descriptions, placement of window in radiating room, following guidelines for minimum area for diagnostic x-ray, dental x-ray, width of wall and dark room, installed radiation notice sticker, installed radiation warning, installed red light indicator for radiating exposure, following guidelines for safety barrier distance, description of diagnostic $x$-ray beam, using radiation barrier, radiation barrier for safety window, and continuant barrier between barriers for surrounding radiation protection were met by UNPAD and UM. These criteria were met by UNPAD and UM because of availability of SOP, adequate instruments, and high supervision.

On the other hand, both UNPAD and UM do not use the pass box in its radiating room, film storage for unprocessed film. Although in UNPAD SOP was available, there were low supervision on the criteria, inadequate of instrument and may be due to insufficient of funds; whereas in UM SOP was unavailable, there were low supervision on the criteria, inadequate of instrument and may be due to insufficient of funds.

Criteria like operate the diagnostic $\mathrm{x}$-ray device with the primary radiation directed to 'minimal placement factor area', and direction of $\mathrm{x}$-ray exposure not to direct to panel control, weaker radiation barrier or simply the use of $x$-ray devices as technique for surrounding radiation protection were met by both UNPAD and UM. These criteria were met by UNPAD because of availability of SOP, adequate instruments, and high supervision; whereas in UM although the SOP was unavailable, it has the advantage of adequate instruments and high supervision.

Subsequent criteria like evaluate patient's condition to monitor radiation exposure, evaluate patient's condition to limit radiation exposure with ALARA, evaluate any radiation accidents, have patient's safety standard, have a standard procedure criteria for pregnant ladies, have a standard of procedure criteria for pediatrics, consult radiologist for clinical indication and temporary diagnosis, consult radiologist for final diagnosis, agreed that transferring radiographic data avoid retaking radiograph, quality control of $x$-ray device is certified, quality control of $\mathrm{x}$-ray device is evaluated routinely, repair and maintenance of $\mathrm{x}$-ray device is done routinely, and practice only the patient taking radiographic photo alone can be in the radiating area, unless required patient's assistant, provide complete radiation protection for patient, use of fast film, use of film-holding device, implementing the right technique and procedure to limit radiation exposure, implementing the optimal radiation safety with ALARA, use exposure factor selection, conventional dental x-ray, digital dental x-ray and film processing system for patient radiation protection were met by both UNPAD and UM. These criteria were met by UNPAD and UM because of availability of SOP, adequate instruments, and high supervision.

Consequent criteria like, have a personnel's radiation safety standard, evaluate operational program aspect in personnel's radiation safety, supervise availability and condition of radiation protection instruments, observe monitoring program at all $\mathrm{x}$-ray device, provide consultation relating to radiation safety, involved in designing radiology facilities, preserve patient's data in a system, identify and organize radiation protection training program, implement radiation protection handling training with obtaining facts in emergency radiation exposure, claimed to report any radiation leakage, prepare written report in radiation protection, follow dosage limit values, have standard limiting dosage, dosage limiting value set by concessioner, avoids repetition of radiation exposure, practice ALARA safety, routinely monitor radiation exposure monthly, and have health report, using film badge for monitoring device, using patient's assistant if necessary of any adult related family; not of operator, no operator allowed in radiating area during radiation exposure, using conventional dental $\mathrm{x}$-ray and digital dental $\mathrm{x}$-ray for personnel or operator radiation protection were met by both UNPAD and UM. These criteria were met by UNPAD because of availability of SOP, adequate instruments, and high supervision; whereas in UM although the SOP was unavailable, it has the advantage of adequate instruments and high supervision.

Such criteria like, provide radiation 
protection near radiation premises, practice film processing in dark room for conventional system, follow dosage limit, routinely check all x-ray device, calculated each designed facility for its maximum work load, use factor for radiation barrier, location area of surrounding facilities, claimed to consider possibility of parameter change in near future for all x-ray device, and has report that contains observation radiation exposure speed of working place and surrounding, routine test $x$-ray beam, dosimeter calibration of each direct reading, facts of radiation leakage or accidents, replacement of x-ray beam component, assessment of personnel's health, practice of commissioning when there is change of location for any radiation device, claimed that periodic inspection is done, radiating area is only for radiating exposure, x-ray beam is never held when operating, use fast speed film, conventional dental x-ray, digital dental x-ray, and use type of film processing system for surrounding radiation protection were met by both UNPAD and UM. These criteria were met by UNPAD and UM because of availability of SOP, adequate instruments, and high supervision.

The advantages of this research were able to create a general picture in describing radiation protection in dentomaxillofacial radiology installations. This standard of radiation protection may be able to be used in other dentomaxillofacial radiology installations throughout Indonesia and Malaysia. Further used of this study may evolve as a reference for Standard Operational Procedure in any dentomaxillofacial radiology installations. The study may also provide insights to management of RSGM-UNPAD and PP-UM in concern of radiation protection.

The weaknesses of this research were that the standard of radiation protection was incomplete. Unfortunately not all ICRP recommendations were stated in this research. Author was unable to obtain complete ICRP recommendations due to insufficient of funds or sponsors. The standard of radiation protection in this study were only limited to the Indonesian and Malaysian government law and legislation. The author was not an expert nor has professional background in concern of radiation protection. Throughout the entire process of obtaining data, author was not accompanied by a Radiography expert in observational survey done. This observation survey may not be comprehensive and only taken in the limited area of understanding of the author concerning radiation protection. The interview survey was conducted through a random sampling of operators, as such the data might be different from a survey that involved every operators.

\section{CONCLUSION}

Radiation protection in Dentomaxillofacial Radiology Installation of RSGM-UNPAD have the advantage of systematic and central way of enforcement of regulation, and the weakness of its standard of radiation protection was not comprehensive, while PP-UM have the advantage of high supervision and adequate of instruments for patient radiation protection, and the weakness of its standard of radiation protection was not comprehensive. Factors influence the result were due to unavailable of SOP, insufficient of funds, inadequate of instruments, low supervision, and difficulty in bureaucracy approval.

\section{REFERENCES}

1. Chmielewski AG, Haji-Saeid M. Radiation technologies: past, present and future. J Radiation Physics and Chemistry 2004;71:1620.

2. Clarke RH, Valentin J. The history of ICRP and the evolution of its policies. ICRP 2008;109:75111.

3. Lochard J, Bogdevitch I, Gallego E, HedemannJensen P, McEwan A, Nisbet A et al. Application of the Commission's Recommendations for the Protection of People in Emergency Exposure Situations. ICRP. 2009;109:109-111.

4. Zahir, S. Country Report in Indonesia. Beijing. 2004. Available online at http://www. slideserve.com/marcellus/cou ntry-reportindonesia

5. Profil. Fakultas Kedokteran Gigi Universitas Padjadjaran. Available from: http://fkg. unpad. ac.id/profil/. 2009

6. Ali, M. Y. 2004. Country report on status of radiation protection in Malaysia. RCA annual report RAS/9/029. Beijing. Available online at http://www.rca.iaea. org/rcamoh3/maina. 
htm.

7. University of Malaya Faculty of Dentistry. Available from: http://dentistry.um.edu. my/ mainpage.php?module=Maklumat\&kateg ori=81\&id=70\&papar=1. 2012.

8. Sedyaningsih DE. Peraturan Menteri Kesehatan Republik Indonesia Nomor 340/MENKES/PER/ III/2010. Jakarta: Menteri Kesehatan Republik Indonesia. 2010. p. 1-14.

9. Iskandar ER. Penerapan keselamatan pasien di pelayanan radiologi. Available from: http:// cafe-radiologi.blogspot.com/2011/10/ penerapa n-keselamatan-pasen-di.html. 2010.

10. Lasman AN. Peraturan Kepala Badan Pengawas Tenaga Nuklir. Jakarta. BAPETEN. 2011. p. 1-42.

11. Suwargiani AA. Gambaran pengetahuan mahasiswa ko-ass mengenai proteksi radiasi pada saat pemotretan foto rontgen. J FKG UNPAD Bandung. 2007:23-33.

12. Laws of Malaysia. Act 304. Atomic Energy Licensing Act 1984. His Majesty's Government Gazette. 2011. p. 1-43.

13. Warta Kerajaan Seri Paduka Baginda. Rang undang undang = His Majesty's Government Gazette. Kuala Lumpur: 2010. p. 404-461.

14. Ismael S, Sastroasmoro S. Dasar Metodologi Penelitian Klinis edisi 2. Jakarta: Sagung Seto. 2002. p. 49-110. 